\title{
THE THIRD FOLIO
}

\section{BY DONALD J. MC GINN}

DR. McGinn is a Professor in the Department of English at Rutgers University.

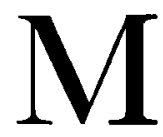

ARKING the four hundredth anniversary of the birth of William Shakespeare, the Rutgers University Library through the generosity of the Curlett $\mathrm{H}$. Wilhelm Book Fund has purchased a fine copy of the Third Folio of his plays. This volume now takes its place between two copies of the Second Folio and one copy of the Fourth. One of the copies of the Second Folio was presented by Gabriel Wells, former rare book dealer and friend of the Library; the other by Rutgers Professor Emeritus Clayton M. Hall. The Fourth Folio was presented by Robert F. Ballantine, Esq.

In order to appreciate the value of this latest acquisition in Shakespeareana it is necessary to know the special importance of the Folios in the whole history of Shakespearean publication. The First Folio is undoubtedly the most important of the four as far as twentiethcentury editors and scholars are concerned. Though its importance was paid lip service by Dr. Samuel Johnson and his friend Edmund Malone in the Eighteenth Century, it was not until 1909, when Alfred W. Pollard published his Shakespeare Folios and Quartos that editors became aware of the true significance of the First Folio. In the first place, it contains the only definitive text for a great many plays which had never before been printed: Julius Caesar, Antony and Cleopatra, Coriolanus, Macbeth, Measure for Measure, and several others. Secondly, it presents corrected versions of some plays that had already been published in quarto. To mention only one, it is probable that the judicious cuts made in the text of the 1604 Quarto of Hamlet before it appeared in the First Folio were personally approved by the playwright himself. Moreover, the entire copy for the First Folio was derived either directly or almost directly from the promptbooks used in the Globe Theatre. In fact, the principal problem for modern editors is to determine, where an earlier quarto version of the play exists, which edition, quarto or Folio, is closer to Shakespeare's own manuscript. 
The next three Folios ( $1632,1664,1685$ ), serve as the tribute of the Seventeenth Century to Shakespeare in attesting to the fact that in no period after his own time was his fame ever in eclipse. Each Folio seems to have been printed from each preceding Folio and thus represents the text of the First Folio along with the "corrections" made in it by the various printers of each succeeding edition. These alterations are generally confined to spelling and syntax. The most important of these occur between the First and the Second Folios, where the press correctors attempt to transform a spoken language, intended for the stage and hence unfettered by bookish impositions, to a written language, prepared for a reading public. The Third and Fourth Folios merely amplify these changes. If any new original sources had been used for this revision, they would have been proudly announced on the new title pages. Not until the Eighteenth Century was any serious attempt made at editing Shakespeare in the modern sense of the word.

Among the last three Folios, however, the Third Folio is unique in that it was published in two issues, the first of which, dated 1663 , is more or less a reprint of the Second Folio, and the second of which, dated I 664, contains seven new plays not included in either of the other earlier Folios. The copy acquired by the Rutgers Library belongs to this second issue. It will not be necessary to belabor the reader with a detailed bibliographical description of this volume, which can be found in Pollard's study, already mentioned, or in the Catalogue of the Parke-Bernet Galleries, from which this copy was purchased. The only particular in which the new acquisition differs from these descriptions is that in being rebound the "Address to the Readers" was accidentally inserted before the "Dedication." An incorrect signature, $A_{2}$ for $A_{3}$, probably is responsible for this mishap.

The bibliographical description of the title page will adequately point up the main difference between the Third Folio and its two predecessors:

$\mathrm{M}^{\mathrm{r}}$ William/Shakespear's/Comedies, Histories, and Tragedies/Published according to the true Original Copies./The third Impression./And unto this Impression is added seven Playes, never/before Printed in Folio./viz./Pericles Prince of Tyre./The London Prodigall./The History of Thomas $\mathrm{L}^{\mathrm{d}}$ Cromwell./Sir John Oldcastle Lord Cobham./The Puritan Widow./ A York- 
shire Tragedy./The Tragedy of Locrine./ [Device with motto: Ad ardua per aspera tendo.] LONDON, Printed for P.C. 1664.

Of the seven additional plays only Pericles is generally accepted as, at least in part, the product of Shakespeare's pen. Indeed, some scholars consider that it has a better claim to this distinction than Titus Andronicus, which was included in the First Folio. Two of these plays, Sir John Oldcastle and the Yorkshire Tragedy, had earlier been published in quarto with "Written by William Shakespeare" on the title page. Of the other four, only the London Prodigall bore Shakespeare's name in full in an early edition. The remaining three plays merely have the initials "W. S." associated with them, either in their entries in the Stationers' Registers or on their title pages.

Since only about two years after the publication of the Third Folio, almost half of the edition was destroyed by the Great Fire, a copy is almost as rare, though of course not as distinguished, as a copy of the First Folio. All that now remains to make the collection complete and perfect would be a First Folio. 